\title{
Ampulla of Vater Neuroendocrine Tumor G1
}

National Cancer Institute

\section{Source}

National Cancer Institute. Ampulla of Vater Neuroendocrine Tumor G1. NCI Thesaurus. Code C95982.

A well differentiated, low grade tumor with neuroendocrine differentiation that arises from the ampulla of Vater and the periampullary region. The mitotic count is less than 2 per 10 HPF. 